\title{
Study of molecular targets influencing homocysteine and cholesterol metabolism in growing rats by manipulation of dietary selenium and methionine concentrations
}

\author{
Nicole M. Wolf ${ }^{1}$, Kristin Mueller ${ }^{1}$, Frank Hirche ${ }^{1}$, Erika Most ${ }^{2}$, Josef Pallauf ${ }^{2}$ and Andreas S. Mueller ${ }^{1 *}$ \\ ${ }^{1}$ Institute of Agricultural and Nutritional Sciences, Preventive Nutrition Group, Martin Luther University Halle Wittenberg, \\ Von-Danckelmann-Platz, 2, D-06120 Halle/Saale, Germany \\ ${ }^{2}$ Institute of Animal Nutrition and Nutritional Physiology, Interdisciplinary Research Centre, Justus Liebig University Giessen, \\ Heinrich-Buff-Ring 26-32, D-35392 Giessen, Germany \\ (Received 3 November 2009 - Revised 15 February 2010 - Accepted 16 February 2010 - First published online 30 March 2010 )
}

Inconsistent results exist from human and animal studies for Se and methionine (Met) regarding their influence on homocysteine (HCys) and cholesterol (Chol) metabolism. To elucidate these contradictions, sixty-four weanling albino rats were divided into eight groups of 8 , and were fed diets containing four different Se levels $(15,50,150$ and $450 \mu \mathrm{g} / \mathrm{kg})$ either in combination with the recommended Met level of $3 \mathrm{~g} / \mathrm{kg}$ (C15, C50, C150 and C450) or with an increased Met concentration of $15 \mathrm{~g} / \mathrm{kg}$ (M15, M50, M150 and M450) for 8 weeks. Plasma HCys was twofold higher in the Se-supplemented C groups than in group C15. Met addition also doubled plasma HCys compared with the respective C groups. In contrast, the expression of the key enzymes of glutathione biosynthesis in the liver was significantly lowered by Se and in particular by Met. Liver Chol concentration was significantly higher in all the Se-supplemented C and M groups than in groups C15 and M15. Plasma Chol was, however, lowered. The uninfluenced expression of sterol-regulatory element-binding protein 2 and of hydroxymethyl-glutaryl-CoA reductase, the increased LDL receptor expression and the reduced expression of the hepatobiliary Chol exporter ATP-binding-cassette-transporter 8 (ABCG8) by Se and/or Met explain these findings. We conclude that the elevation of plasma HCys in rats by Se and Met results from a higher export into plasma. The fact that Se in particular combined with Met increases liver Chol but reduces plasma Chol should be addressed in future investigations focussing on the regulation of ABCG8, which is also selectively involved in the reverse transport of phytosterols in the small intestine.

Selenium: Methionine: Homocysteine: Cholesterol: Gene expression

Results obtained from human and animal studies suggest that an elevated plasma homocysteine (HCys) concentration may promote the early development of coronary artery disease and ischaemic stroke ${ }^{(1)}$. The generation of reactive oxygen species $^{(2)}$, subsequently leading to increased LDL oxidation ${ }^{(3)}$, the generation of vascular injury via the increased expression and liberation of proinflammatory transcription factors and cytokines $^{(4-6)}$ as well as reduced vessel relaxation via decreased NO availability ${ }^{(7)}$ are discussed as mechanisms underlying the proatherogenic effects of HCys. With the exception of inherited disorders in methionine (Met) and HCys metabolism such as cystathione- $\beta$-synthase (CBS) or Met synthase deficiency or polymorphisms in these genes, hyperhomocysteinaemia is assumed as being influenced by various nutritional components ${ }^{(8)}$. Currently, the influence of folic acid, vitamin $B_{12}$ and vitamin $B_{6}$ status as well as the effectiveness of the supplementation of these vitamins in lowering HCys concentration and reducing the risk and recurrence of CVD and ischaemic stroke is the subject of controversial discussion $^{(9-11)}$. Despite evidence and inconsistent data on the beneficial effects of vitamin B supplementation in CVD and ischaemic stroke, the American Heart and Stroke Association and the German, Austrian and Swiss Homocysteine Society advise treating patients with hyperhomocysteinaemia or with a history of transient ischaemic attacks or stroke daily with a standard multivitamin preparation in order to achieve the recommended daily amounts of $0.4 \mathrm{mg}$ folic acid, $2.4 \mu \mathrm{g}$ vitamin $\mathrm{B}_{12}$ and $1.7 \mathrm{mg}$ vitamin $\mathrm{B}_{6}^{(12,13)}$. The results of the National Nutrition Survey II revealed a deficit in folic acid intake in the German population also, and subsequently, a fortification of selected foods with folic acid is under consideration ${ }^{(14)}$. Other important factors determining plasma HCys concentration are age, sex and renal status ${ }^{(15,16)}$. In recent years, contradictory results have also been reported with regard to the influence of the trace element Se on HCys metabolism. Whereas studies with chicks ${ }^{(17)}$ and with

\footnotetext{
Abbreviations: ABCG8, ATP-binding-cassette-transporter 8; BHMT, betaine hydroxymethyltransferase; CBS, cystathione- $\beta$-synthase; Chol, cholesterol; GCLC, glutamate cysteine ligase, catalytic subunit; GCLM, glutamate cysteine ligase, modulatory subunit; GPx, glutathione peroxidase; GS, glutathione synthetase; HCys, homocysteine; HMGCoAR, hydroxymethyl-glutaryl CoA reductase; LDLR, LDL receptor; Met, methionine; PE, phosphatidylethanolamine; SREBP2, sterol-regulatory element-binding protein 2; $T_{\mathrm{a}}$, annealing temperature.

* Corresponding author: Andreas S. Mueller, fax +49 34555 27124, email andreas.mueller@landw.uni-halle.de
} 
mice and rats ${ }^{(18-21)}$ showed that Se-deficient animals had an impressively reduced plasma HCys concentration than their littermates supplemented with the recommended dietary Se amount or with supranutritional Se, human cross-sectional observational studies with elderly people from Spain ${ }^{(22)}$, Upper Silesia $^{(23)}$ and the $\mathrm{UK}^{(24)}$ uniquely showed an inverse correlation between Se status and plasma HCys concentration. Another study with a middle-aged Inuit population also demonstrated the inverse correlation between Se status and plasma HCys concentration ${ }^{(25)}$. Both in a 20 -week intervention trial in New Zealand whereby 189 volunteers aged 18-64 years were supplemented with a placebo or $200 \mu \mathrm{g}$ $\mathrm{Se} / \mathrm{d}$ as selenomethionine ${ }^{(26)}$ and in an intervention trial in the UK with 501 elderly people who were supplemented with a placebo or 100,200 or $300 \mu \mathrm{g}$ Se/d as high Se yeast for 6 months $^{(27)}$, Se supplementation had no influence on plasma HCys level. However, the results of a rat study demonstrated a significant reduction of plasma HCys concentration in Se-supplemented rats fed diets supplemented simultaneously with a diet containing a high folic acid concentration of $2 \mathrm{mg} / \mathrm{kg}^{(19)}$. Besides the feeding of Se-rich diets, the feeding of Met-rich diets to rats is accepted as a means of increasing their plasma HCys level ${ }^{(28,29)}$. Results of the impact of dietary Met on plasma HCys in human subjects vary with regard to the critical dietary Met amount. Whereas some reports suggest that about fivefold of the recommended Met amount is necessary to produce a considerable increase in plasma HCys concentration ${ }^{(30,31)}$, another study with Dutch men found a distinct postprandial increase in plasma HCys concentration lasting about $6 \mathrm{~h}$ in healthy men given a high protein diet $(21 \% \text { energy })^{(32)}$. Results from a Finish study with men suggest an association between a slightly increased daily Met intake between 25 and $40 \mathrm{mg} / \mathrm{kg}$ body weight and a $31 \%$ higher risk of coronary problems ${ }^{(33)}$. Feeding Met-rich diets to rats and subjecting human subjects to a Met-loading test additionally effected an increase in plasma cholesterol (Chol) concentration, representing another risk factor for the accelerated development of atherosclerosis ${ }^{(28,29,34)}$. Moreover, data from two large cross-sectional observational trials from the USA and the UK found that a high Se status was positively associated with increased plasma values for total Chol and LDL Chol ${ }^{(35,36)}$. However, combined effects of dietary Se and Met on HCys and Chol metabolism have not been investigated to date. Consequently, we have designed a trial with growing rats to study the effects of different dietary Se concentrations (Se deficiency, half the recommended dietary amount, recommended dietary amount and three times the recommended dietary amount) and of two dietary Met concentrations (recommended dietary amount and five times the recommended dietary amount) on the HCys and Chol metabolism of these animals. Taking into consideration both the recommendations and species differences between human subjects and rats, we have chosen the Se and Met supplementation range in a way that allows transferability of the data.

\section{Methods and materials}

\section{Rats and diets}

The protocol of the rat nutrition study was approved by the Regional Council of Giessen and by the Animal Welfare
Committee of the Justus Liebig University of Giessen (record token: V54-19c20/15cGI 19/3). Sixty-four healthy growing male rats (initial body weight, 64.2 (SE 0.25) g from the Interdisciplinary Research Center, Department of Animal Nutrition and Nutritional Physiology's own strain (HK 51) were randomly assigned to eight groups of 8 . The Se-deficient basal diet of group C15 had an analysed Se concentration of approximately $15 \mu \mathrm{g} / \mathrm{kg}$, and was based on Torula yeast and Se-deficient wheat (Table 1). The diets for groups C50 (one-third of the recommended dietary Se level), C150 (recommended dietary Se level) and C450 (three times the recommended dietary Se level) were supplemented with 50, 150 and $450 \mu \mathrm{g} \mathrm{Se} / \mathrm{kg}$ diet as sodium selenate. The diets for groups $\mathrm{C} 15, \mathrm{C} 50, \mathrm{C} 150$ and $\mathrm{C} 450$ were supplemented with $3.0 \mathrm{~g} \mathrm{DL}-\mathrm{Met} / \mathrm{kg}$ to adjust the Met level to the requirement of the growing rats. The high Met diets of groups M15, M50, M150 and M450 had dietary Se levels that were the same as those of the diets of the respective $\mathrm{C}$ groups, but were supplemented with fivefold Met amount $(15 \mathrm{~g} / \mathrm{kg})$. With the exception of the variations in Se and Met concentrations, the diets were composed according to the American Institute of Nutrition-93G recommendations ${ }^{(37)}$. The rats were kept individually, and had ad libitum access to the diet and bidistilled water. After 8 weeks, the animals were decapitated under $\mathrm{CO}_{2}$. The livers were excised, frozen in liquid $\mathrm{N}_{2}$ and stored at $-80^{\circ} \mathrm{C}$ until further analysis. Blood was collected in heparinised tubes, and was centrifuged for $20 \mathrm{~min}$ at $3000 \mathrm{~g}$ for plasma preparation. Plasma was stored at $-80^{\circ} \mathrm{C}$ until analysis.

Table 1. Composition of the basal diet

\begin{tabular}{|c|c|}
\hline Ingredient & $\mathrm{g} / \mathrm{kg}$ diet \\
\hline Torula yeast (Attisholz, Solothurn, Switzerland) & $250 \cdot 0$ \\
\hline $\begin{array}{l}\text { Se-deficient wheat (harvested in the Vogelsberg region } \\
\text { in Hesse, Germany) }\end{array}$ & $100 \cdot 0$ \\
\hline Cellulose BWW 40 (Rettenmaier, Rosenberg, Germany) & $50 \cdot 0$ \\
\hline Glucose (Sigma-Aldrich, St Louis, MO, USA) & $50 \cdot 0$ \\
\hline Sucrose (Suedzucker, Mannheim, Germany) & $50 \cdot 0$ \\
\hline Soya bean oil (Hesse) & $50 \cdot 0$ \\
\hline dl-Met (Degussa, Dusseldorf, Germany)* ${ }^{*}$ & 3.00 \\
\hline I-Trp (Sigma-Aldrich)† & 0.50 \\
\hline Mineral premix (all salts from Sigma-Aldrich)‡ & $35 \cdot 0$ \\
\hline $\begin{array}{l}\text { Vitamin premix (all vitamins from Roche, } \\
\text { Basel, Switzerland)§ }\end{array}$ & $10 \cdot 0$ \\
\hline Cholin chloride (BASF, Mannheim, Germany) & 2.00 \\
\hline Maize starch (Roquette, Lestrem, France) & 399.5 \\
\hline Se premix\| & 0.00 \\
\hline Total & $1000 \cdot 0$ \\
\hline
\end{tabular}

* In the diets of groups M15, M50, M150 and M450, the amount of methionine in the basal diet was increased to $15 \mathrm{~g} / \mathrm{kg}$ by replacing maize starch.

$\dagger$ Added according to the American Institute of Nutrition-93G recommendations ${ }^{(37)}$.

$\ddagger$ Considering the high natural concentrations of $\mathrm{Ca}, \mathrm{K}, \mathrm{Mg} \mathrm{P}, \mathrm{Cu}, \mathrm{Fe}$ and $\mathrm{Zn}$ of Torula yeast, the following mineral amounts were added to $1 \mathrm{~kg}$ complete diet with $35 \mathrm{~g} / \mathrm{kg}$ of the concentrated premix to achieve the recommended amounts ${ }^{(37)}$. $\mathrm{Ca}, 3.0 \mathrm{~g}\left(\mathrm{CaCO}_{3}\right) ; \mathrm{Mg}, 228 \mathrm{mg}\left(\mathrm{MgSO}_{4} .7 \mathrm{H}_{2} \mathrm{O}\right) ; \mathrm{Cu}, 2.50 \mathrm{mg}\left(\mathrm{CuSO}_{4} .5 \mathrm{H}_{2} \mathrm{O}\right)$; $\mathrm{Mn}, 8.62 \mathrm{mg}\left(\mathrm{MnSO}_{4} . \mathrm{H}_{2} \mathrm{O}\right) ; \mathrm{Na}, 1.02 \mathrm{~g}(\mathrm{NaCl}) ; \mathrm{K}, 741 \mathrm{mg}\left(\mathrm{K}_{3} \mathrm{C}_{6} \mathrm{H}_{5} \mathrm{O}_{7} . \mathrm{H}_{2} \mathrm{O}\right) ; \mathrm{Cr}$, $1.00 \mathrm{mg}\left(\mathrm{KCR}\left(\mathrm{SO}_{4}\right)_{2} .12 \mathrm{H}_{2} \mathrm{O}\right) ; \mathrm{B}, 0.51 \mathrm{mg}\left(\mathrm{H}_{3} \mathrm{BO}_{3}\right) ; \mathrm{Ni}, 0.49 \mathrm{mg}\left(\mathrm{NiSO}_{4} .6 \mathrm{H}_{2} \mathrm{O}\right)$; $\mathrm{F}, 1.00 \mathrm{mg}(\mathrm{NaF}) ; \mathrm{Si}, 5.00 \mathrm{mg}\left(\mathrm{Na}_{2} \mathrm{SiO}_{3} .9 \mathrm{H}_{2} \mathrm{O}\right) ; \mathrm{Li}, 0.10 \mathrm{mg}(\mathrm{LiCl}) ; \mathrm{Mo}, 0.16 \mathrm{mg}$ $\left(\mathrm{H}_{24} \mathrm{Mo}_{7} \mathrm{~N}_{6} \mathrm{O}_{24} .4 \mathrm{H}_{2} \mathrm{O}\right) ; \mathrm{I}, 0.23 \mathrm{mg}(\mathrm{KI}) ; \mathrm{V}, 0.09 \mathrm{mg}\left(\mathrm{NH}_{4} \mathrm{VO}_{3}\right)$.

$\S$ All vitamins were added according to the recommendations ${ }^{(37)}$ without any corrections.

|| In the Se-supplemented groups, maize starch was replaced with $8.33 \mathrm{~g}$ (C50 and M50), $25 \mathrm{~g}$ (C150 and M150), and $75 \mathrm{~g}$ (C450 and M450) of the Se premix containing $6 \mathrm{mg} \mathrm{Se} / \mathrm{kg}$ as sodium selenate in order to adjust the final Se concentrations of 50,150 and $450 \mu \mathrm{g} / \mathrm{kg}$. 


\section{Selenium assay}

Se concentration in the diets and livers was measured by hydride generation atomic absorption spectrometry (Unicam PU 9400 X; PU 3960 X) as described previously ${ }^{(38)}$. Certified samples from the National Institute of Standard and Technology (soft winter wheat starch, no. 8438 and bovine liver, no. $1577 \mathrm{~b}$ ) and from Medichem (control serum, Metalle S; Steinenbronn, Germany) served as the reference materials for Se determination in the different matrices.

\section{Liver glutathione peroxidase 1 and plasma glutathione peroxidase 3}

Glutathione peroxidase (GPx) 1 and GPx3 activity was measured spectrophotometrically (Carry 50; Varian, Darmstadt, Germany) using the assay method coupled to GSH reductase at $340 \mathrm{~nm}^{(39)}$. NADPH oxidation, which is proportional to GPX-dependent peroxide reduction, was recorded for $3 \mathrm{~min}$. GPx1 activity was analysed in the rat liver cytosol diluted with $50 \mathrm{mmol} / 1$ phosphate buffer, and GPx3 activity was analysed in the undiluted plasma. For both enzymes, $\mathrm{H}_{2} \mathrm{O}_{2}$ served as the substrate. One unit of GPx1 and GPx3 activity was defined as $1 \mu \mathrm{mol} \mathrm{NADPH}$ oxidised per minute and normalised to $1 \mathrm{mg}$ protein.

\section{Protein concentration in the liver cytosol and in plasma}

The protein concentration of the liver cytosol and of plasma was determined according to a standard protocol ${ }^{(40)}$ in microtitre plates using the plate reader Tecan SpectraFluor Plus (Tecan, Grödig, Austria).

\section{Total GSH and total homocysteine in the liver and plasma}

Plasma and liver Hcys were measured with modifications of a procedure described earlier ${ }^{(41)}$ using reversed-phase HPLC on a 100 RP-18e column (Agilent Technologies, Santa Clara, CA, USA). In brief, $10 \mu$ l of the internal standard mercaptopropionylglycine $(200 \mu \mathrm{mol})$ per litre potassium borate buffer 1 (100 mM-trihydrogen borate and 2.0 mM-EDTA, $\mathrm{pH} 9.5$ ) were added to $30 \mu \mathrm{l}$ of undiluted plasma. The samples were mixed thoroughly. To reduce protein disulphide bonds and to liberate reduced thiols, $4.0 \mu \mathrm{l}$ of a mixture of tri- $N$-butylphosphate-dimethylformamide $(1: 1, \mathrm{v} / \mathrm{v})$ were added. After $30 \mathrm{~min}$ of incubation and centrifugation, protein precipitation was carried out by the addition of $25 \mu \mathrm{l}$ of $0.6 \mathrm{M}$-perchloric acid containing $1.0 \mathrm{~mm}$-EDTA. After $15 \mathrm{~min}$ of incubation at $20^{\circ} \mathrm{C}$, the samples were centrifuged for $10 \mathrm{~min}$ at $10000 \mathrm{~g}$. Twenty microlitres of the supernatant were diluted with potassium borate buffer $2(2.0 \mathrm{M}$-trihydrogen borate and $5 \mathrm{~mm}$-EDTA, $\mathrm{pH} 10 \cdot 5)$. Following thorough mixing, $20 \mu \mathrm{l}$ of a $0.1 \%$ (w/v) 7-fluorobenzofurazone-4-sulphonic acid ammonium salt solution in potassium borate buffer 3 (2.0 M-trihydrogen borate, $\mathrm{pH} 9.5$ ) were added. After $60 \mathrm{~min}$ of incubation in a thermo mixer at $60^{\circ} \mathrm{C}$, samples were cooled on ice, mixed and centrifuged for $10 \mathrm{~min}$ at $10000 \mathrm{~g}$. Sixty microlitres of the supernatant were pipetted into dark HPLC vials and put into the autosampler. The injection volume was $10 \mu \mathrm{l}$. The elution profile was as follows: $6.5 \mathrm{~min}$ eluent A (0.10 M-sodium acetate buffer containing
$2 \%$ (v/v) methanol, $\mathrm{pH} 4 \cdot 0), 7.5$ min eluent B (0.1 M-sodium phosphate buffer containing $5 \%(\mathrm{v} / \mathrm{v})$ methanol, $\mathrm{pH} 6 \cdot 0)$, 3.0 min eluent B and 3.0 min eluent A. Fluorescence detection was carried out at an excitation wavelength of $385 \mathrm{~nm}$ and an emission wavelength of $515 \mathrm{~nm}$. A calibrator plasma with known HCys and GSH concentrations was carried along to calculate sample concentrations of total GSH and HCys. For GSH and HCys determination in the livers, 1:5 $(\mathrm{w} / \mathrm{v})$ homogenates were prepared in ice-cold PBS. The remaining procedure was the same as described above for the undiluted plasma.

\section{Cholesterol concentration in plasma and liver}

Total Chol concentration in the liver and plasma was determined using the commercial test kits Ecoline ${ }^{\circledR} \mathrm{S}+$ from DiaSys Diagnostic Systems GmbH (Holzheim, Germany). Ten microlitres of undiluted plasma were used for Chol determination with the test kit. Before liver Chol analysis, total liver lipids were extracted with a hexane-isopropanol $(3: 2, \quad v / v)$ mixture $^{(42)}$. Fifty-microlitre aliquots of these lipid extracts were evaporated under $\mathrm{N}_{2}$ gassing, and the remaining lipids were resolved in $50 \mu \mathrm{l}$ of a Triton $\mathrm{X}-100$-chloroform mixture $(1: 1, \mathrm{v} / \mathrm{v})^{(43)}$. After evaporation of the chloroform, $10 \mu \mathrm{l}$ of the Triton X-100 extracts were used for Chol determination with the test kit. Chol concentration in all the liver and plasma samples was measured in duplicate.

mRNA expression of glutathione peroxidase 1, glutathione S-transferase $\alpha 2$, glycine-N-methyltransferase, cystathione$\beta$-synthase, S-adenosylmethionine decarboxylase, betaine hydroxymethyltransferase, glutamate cysteine ligase, modulatory subunit, glutamate cysteine ligase, catalytic subunit and glutathione synthetase in the liver

Liver RNA was extracted with TRIzol reagent (Invitrogen, Karlsruhe, Germany) according to the manufacturer's protocol. Following reverse transcription of $3.0 \mu \mathrm{g}$ of total RNA using a commercial complementary DNA synthesis kit (RevertAid $^{\mathrm{TM}}$ First Strand synthesis kit; Fermentas, Vilnius, Latvia), the complementary DNA solutions were diluted 2:3 $(\mathrm{v} / \mathrm{v})$ with diethyl pyrocarbonate-treated sterile water for use in real-time detection PCR. For the amplification of specific sequences of the genes investigated, the RotorGene $6000^{\mathrm{TM}}$ real-time detection PCR apparatus (Corbett Research, Mortlake, NSW, Australia) was used.

Amplification data were analysed with the RotorGene $6000^{\mathrm{TM}}$ series software using the amplification efficiencies and the $C_{\mathrm{t}}$ values ${ }^{(44)}$. The expression of the single genes was normalised to $\beta$-actin expression.

The primers used in PCR and their gene bank accession numbers are as follows: GPx1 (NM030826), primer forward $\left(5^{\prime} \rightarrow 3^{\prime}\right)$ : TCA TTG AGA ATG TCG CGT CT, primer reverse $\left(5^{\prime} \rightarrow 3^{\prime}\right)$ : CCC ACC AGG AAC TTC TCA AA (annealing temperature $\left.\left(T_{\mathrm{a}}\right): 55^{\circ} \mathrm{C}\right)$; glycine- $N$-methyltransferase (NM017084), primer forward $\left(5^{\prime} \rightarrow 3^{\prime}\right)$ : CCA CCG CAA CTA CGA CTA CA, primer reverse $\left(5^{\prime} \rightarrow 3^{\prime}\right)$ : TCT TCT TGA GCA CGT GGA TG $\left(T_{\mathrm{a}}: 57^{\circ} \mathrm{C}\right)$; CBS (NM012522), primer forward $\left(5^{\prime} \rightarrow 3^{\prime}\right)$ : ATG CTG CAG AAA GGC TTC AT, primer reverse $\left(5^{\prime} \rightarrow 3^{\prime}\right)$ : GCG GTA TTG GAT CTG 
CTC AT $\left(T_{\mathrm{a}}: 55^{\circ} \mathrm{C}\right)$; betaine hydroxymethyltransferase (BHMT; NM030850), primer forward $\left(5^{\prime} \rightarrow 3^{\prime}\right)$ : GCA CCA GCT TGC AGA CAA TA, primer reverse $\left(5^{\prime} \rightarrow 3^{\prime}\right)$ : TGT GCA TGT CCA AAC CAC TT $\left(T_{\mathrm{a}}: 55^{\circ} \mathrm{C}\right) ; S$-adenosylmethionine decarboxylase (NM031011), primer forward $\left(5^{\prime} \rightarrow 3^{\prime}\right)$ : CCC AGC AGT TAT GGA CCA GT, primer reverse $\left(5^{\prime} \rightarrow 3^{\prime}\right)$ TCC ATC CGA TTT CAT TCC AT $\left(T_{\mathrm{a}}: 55^{\circ} \mathrm{C}\right)$; glutathione synthetase (GS; NM012962), primer forward $\left(5^{\prime} \rightarrow 3^{\prime}\right)$ : AGA TGG CTA CAT GCC CAG TC, primer reverse $\left(5^{\prime} \rightarrow 3^{\prime}\right)$ : TGT CTT TCA GCT GCT CCA GA $\left(T_{\mathrm{a}}\right.$ : $57^{\circ} \mathrm{C}$ ); glutamate cysteine ligase, catalytic subunit (GCLC; NM012815), primer forward $\left(5^{\prime} \rightarrow 3^{\prime}\right)$ : CCA CAA ACT GGC AGA CAA TG, primer reverse $\left(5^{\prime} \rightarrow 3^{\prime}\right)$ : TCC TTC CCA TTG ATG ATG GT $\left(T_{\mathrm{a}}: 55^{\circ} \mathrm{C}\right)$; glutamate cysteine ligase, modulatory subunit (GCLM; NM017305), primer forward $\left(5^{\prime} \rightarrow 3^{\prime}\right)$ : AGG CAC CTC GGA TCT AGA CA, primer reverse $\left(5^{\prime} \rightarrow 3^{\prime}\right)$ : AAA TCT GGT GGC ATC ACA CA $\left(T_{\mathrm{a}}: 55^{\circ} \mathrm{C}\right)$; glutathione $S$-transferase $\alpha 2$ (NM031509), primer forward $\left(5^{\prime} \rightarrow 3^{\prime}\right)$ : GGG GAG AAA GAG GCA AGT CT, primer reverse $\left(5^{\prime} \rightarrow 3^{\prime}\right)$ : CTT CAG CAG AGG GAA GTT GG $\left(T_{\mathrm{a}}: 57^{\circ} \mathrm{C}\right)$; sterol-regulatory element-binding protein 2 (SREBP2; NM001033694), primer forward $\left(5^{\prime} \rightarrow 3^{\prime}\right)$ : ATC CGC CCA CAC TCA CGC TCC TC, primer reverse $\left(5^{\prime} \rightarrow 3^{\prime}\right)$ : GGC CGC ATC CCT CGC ACT $\mathrm{G} \quad\left(T_{\mathrm{a}}: 65^{\circ} \mathrm{C}\right) ;$ hydroxymethyl-glutaryl $\mathrm{CoA}$ reductase (HMGCoAR; NM013134), primer forward $\left(5^{\prime} \rightarrow 3^{\prime}\right)$ : AAG GGG CGT GCA AAG ACA ATC, primer reverse $\left(5^{\prime} \rightarrow 3^{\prime}\right)$ : ACG GCA CGG AAA GAA CCA TAG T $\left(T_{\mathrm{a}}: 57^{\circ} \mathrm{C}\right)$; ATPbinding-cassette-transporter 8 (ABCG8; NM130414), primer forward $\left(5^{\prime} \rightarrow 3^{\prime}\right)$ : AGA CCC TCA CAC AGG ACA CC, primer reverse $\left(5^{\prime} \rightarrow 3^{\prime}\right)$ : CAG TCC GTC CTC CAG TTC AT $\left(T_{\mathrm{a}}: 59^{\circ} \mathrm{C}\right)$; LDL receptor (LDLR; NM175762), primer forward $\left(5^{\prime} \rightarrow 3^{\prime}\right)$ : AGA ACT GCG GGG GCC GAA GAC AC, primer reverse $\left(5^{\prime} \rightarrow 3^{\prime}\right)$ : AAA CCG CTG GGA CAT AGG CAC TCA $\left(T_{\mathrm{a}}: 60^{\circ} \mathrm{C}\right)$; $\beta$-actin (NM031144), primer forward $\left(5^{\prime} \rightarrow 3^{\prime}\right)$ : ATC GTG CGT GAC ATT AAA GAG AAG, primer reverse $\left(5^{\prime} \rightarrow 3^{\prime}\right)$ : GGA CAG TGA GGC CAG GAT AGA G $\left(T_{\mathrm{a}}: 60^{\circ} \mathrm{C}\right)$.

Relative mRNA expression levels are expressed as $x$-fold changes compared with group $\mathrm{C} 15$.

\section{Statistical analysis}

The data were analysed by one-way ANOVA using the SPSS Statistical Package 14.0 for Windows (Chicago, IL, USA). Homogeneity of variances was tested using the Levene test. If variances were homogenous, differences of means $(P<0.05)$ were evaluated with the least significant difference test, if not the Games-Howell test was used.

\section{Results}

Diets and rat performance variables (diet consumption, live weight and feed efficiency)

The dietary Se concentrations scheduled in the experimental design were confirmed by Se analysis (C15, 14.8 (SE 2.94); C50, 49.7 (SE 3.73); C150, 156 (SE 7.12); C450, 488 (SE 9.51); M15, 16.2 (SE 4.73); M50, 47 (SE 4.02); M150, 149 (SE 2.27); M450, 493 (SE 14.65)). At the beginning of the experiment, body weight did not differ among the groups (Table 2).

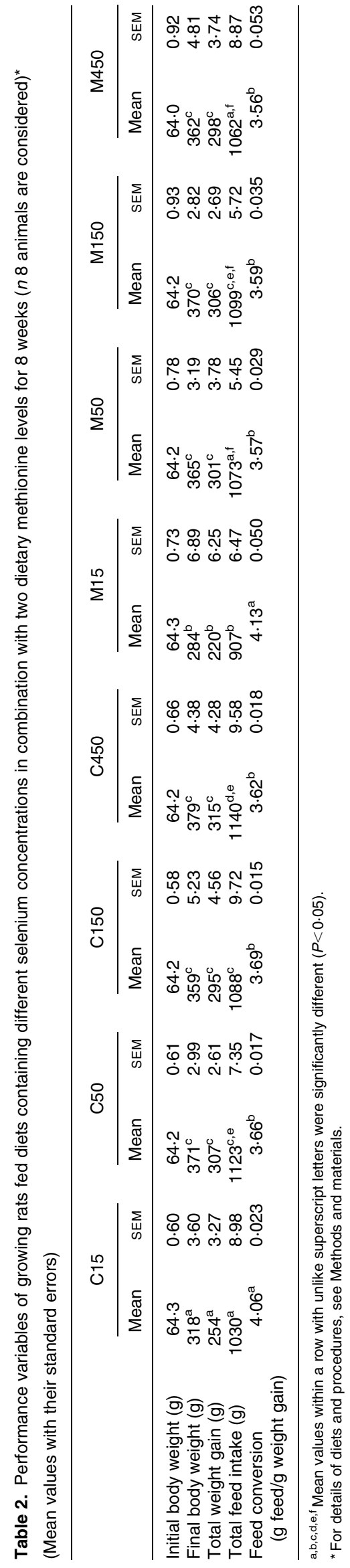


For rats receiving the Se-deficient diets either in combination with the recommended Met concentration or with a high Met concentration (C15 and M15), the total feed intake over 8 weeks and feed efficiency were significantly impaired compared with their respective Se-supplemented companions. In nearly all cases, the mean total feed intake of the rats with the high dietary Met concentration was significantly lower than that of the groups with the recommended Met concentration (C15 v. M15, C50 v. M50 and C450 v. M450). Corresponding to the improved feed conversion, all Se-supplemented rats of both dietary Met levels had significantly higher final body weights than their controls. Whereas the final body weight in the high Met Se-deficient rats (M15) was significantly lower than that in their companions with the recommended Met concentration (C15), no differences in the final body weight existed between the matching Se-supplemented groups at the other dietary Se levels $(50,150$ and $450 \mu \mathrm{g} / \mathrm{kg}$ ).

Selenium status, variables of the selenium- and glutathionedependent redox system in the liver and plasma, and homocysteine concentration in the liver and plasma

The liver Se concentration in the Se-deficient rats of groups C15 and M15 was reduced to 1.7 and $1.5 \%$ of the concentrations in groups C450 and M450 (Table 3). At both dietary Met levels, the gradual increase in Se supplementation from 50 to $450 \mu \mathrm{g} / \mathrm{kg}$ increased the liver Se concentration approximately twofold in each case. With the exception of groups $\mathrm{C} 150$ and M150, the liver Se concentration in the other corresponding groups (C15 v. M15, C50 v. M50 and C450 v. M450) was significantly higher in the $\mathrm{C}$ groups with the recommended dietary Met concentration. At both Met levels with Se deficiency (C15 and M15), GPx1 mRNA expression was approximately fivefold lower than that in the Se-supplemented rats (C50, C150, C450, M50, M150 and M450). Rats supplemented with $50 \mu \mathrm{g}$ Se/kg (C50 and M50) already had a GPx1 mRNA expression, which was comparably as high as that in rats supplemented with 150 and $450 \mu \mathrm{g}$ $\mathrm{Se} / \mathrm{kg}$. No influence of the dietary Met level on GPx1 mRNA expression could be analysed. In contrast to GPx 1 expression, the expression of the phase II enzyme glutathione $S$-transferase (glutathione $S$-transferase $\alpha 2$ ), another sensitive indicator of Se deficiency, was 1.5- to 2.5-fold higher in Se-deficient rats than in their Se-supplemented companions. Liver GPx1 activity in $\mathrm{C} 15$ and M15 rats was reduced to approximately $1 \%$ of the activity of groups C150, C450, M150 and M450. Liver GPx1 activity of rats of groups C50 and M50 was 40-60\% lower than that of their companions supplemented with the recommended Se amount (C150 and M150) or with slightly supranutritional Se supplementation (C450 and M450). As observed for the liver Se concentration, the liver GPx1 activity of rats with the high dietary Met supplementation was lower than the activity of their companions fed the diets with the recommended dietary Met concentration. However, with the exception of groups C50 and M50, this effect was not statistically significant. Plasma Se concentration in $\mathrm{C} 15$ and M15 rats was decreased to 2.5 and $4.3 \%$ of the concentration in groups C450 and M450. Plasma Se concentration gradually and significantly increased when the dietary Se concentration was raised from 50 to $450 \mu \mathrm{g} / \mathrm{kg}$.
In contrast to the liver Se concentration, plasma Se concentration was not influenced by the dietary Met concentration. GPx3 activity in the Se-deficient groups C15 and M15 was reduced to approximately $3 \%$ of the activity in groups $\mathrm{C} 450$ and M450. In groups C50 and M50, GPx3 reached an activity of approximately $70 \%$ of that in the respective groups receiving diets containing the recommended Se concentration (C150 and M150) or a slightly supranutritional Se supplementation (C450 and M450). In the Se-deficient groups $\mathrm{C} 15$ and M15, plasma GPx3 activity dropped to $3 \cdot 0-3.5 \%$ of that in groups $\mathrm{C} 150$ and M150 supplemented at the recommended level. However, in contrast to liver GPx1 activity, plasma GPx3 activity in the Se-supplemented rats of groups M50 and M150 fed the high dietary Met concentration was significantly higher than that in their companions in groups $\mathrm{C} 50$ and $\mathrm{C} 150$ on diets with the recommended Met level. For groups M450 and C450, a distinct trend $(P=0.061)$ existed with regard to this effect. At both dietary Met levels, total liver GSH concentration was significantly higher in $\mathrm{C} 15$ and M15 rats than in the respective Se-supplemented groups. Independent of the dietary Se concentration, rats receiving the diets with the high Met concentration had a significantly higher liver GSH concentration than the corresponding groups receiving diets with the recommended dietary Met level. Liver HCys concentration was 1.4- to 1.5-fold higher in Se-deficient rats of groups C15 and M15 than in their Se-supplemented companions. In contrast to the effect observed for GSH, the higher dietary Met concentration had no influence on liver HCys concentration with the exception of groups C50 and M50. Whereas both the liver GSH concentration and the liver HCys concentration decreased in a dose-dependent manner due to increasing Se supplementation at both dietary Met levels, a completely different regulation profile of the plasma concentration of both compounds could be observed. At both dietary Met levels, increasing the Se supplementation of the diets led to a reduction of total plasma GSH concentration in a dose-dependent manner. Thus, the lowest plasma GSH values could be measured in groups C450 and M450. Moreover, rats receiving the diets with the high Met concentration (groups M15, M50, M150 and M450) had in each case a significantly lower plasma GSH concentration than the respective $\mathrm{C}$ groups $\mathrm{C} 15, \mathrm{C} 50, \mathrm{C} 150$ and $\mathrm{C} 450$. In contrast, total plasma HCys concentration was the lowest in the Se-deficient group C15 with the recommended dietary Met level. Se addition to the diets approximately doubled plasma HCys levels. However, a dose-dependent effect of the different dietary Se levels on plasma HCys concentration could not be analysed. The addition of the high dietary Met concentration to the diets (rats of groups M15, M50, M150 and M450) again approximately doubled plasma HCys concentration in comparison to the groups C15, C50, C150 and $\mathrm{C} 450$. As analysed in the $\mathrm{C}$ groups, also in the $\mathrm{M}$ groups, a significant increase in plasma HCys concentration existed only between the Se-deficient group M15 and all groups with Se supplementation (M50, M150 and M450), whereas an increase in dietary Se supplementation did not lead to a further rise in plasma HCys level. On the contrary, in M450 rats, even a small but significant decline in plasma HCys concentration could be analysed compared with groups M50 and M150 with lower Se supplementation. 
Table 3. Effects of different dietary selenium concentrations in combination with two dietary methionine levels on liver and plasma selenium concentrations, total liver and plasma GSH and homocysteine (HCys) concentrations, and the activity as well as the expression of glutathione peroxidase (GPx) 1 , GPx3 and glutathione $S$-transferase $\alpha 2$ (GSTA2) of growing rats ( 8 animals are considered) ${ }^{*}$ (Mean values with their standard errors)

\begin{tabular}{|c|c|c|c|c|c|c|c|c|c|c|c|c|c|c|c|c|}
\hline & \multicolumn{2}{|c|}{$\mathrm{C} 15$} & \multicolumn{2}{|c|}{ C50 } & \multicolumn{2}{|c|}{ C150 } & \multicolumn{2}{|c|}{ C450 } & \multicolumn{2}{|c|}{ M15 } & \multicolumn{2}{|c|}{ M50 } & \multicolumn{2}{|c|}{ M150 } & \multicolumn{2}{|c|}{ M450 } \\
\hline & Mean & SEM & Mean & SEM & Mean & SEM & Mean & SEM & Mean & SEM & Mean & SEM & Mean & SEM & Mean & SEM \\
\hline \multicolumn{17}{|l|}{ Liver } \\
\hline $\mathrm{Se}(\mathrm{nmol} / \mathrm{g}$ fresh matter) & $0.91^{a}$ & 0.13 & $26 \cdot 1^{\mathrm{c}}$ & 0.70 & $54 \cdot 3^{\mathrm{d}}$ & 1.93 & $98 \cdot 2^{f}$ & 3.31 & $0.87^{\mathrm{a}}$ & 0.18 & $22 \cdot 6^{\mathrm{b}}$ & 0.67 & $55 \cdot 3^{\mathrm{d}}$ & 0.88 & $86.4^{\mathrm{e}}$ & 2.76 \\
\hline GPX1 activity (mU/mg prot.) & $6 \cdot 16^{\mathrm{a}}$ & 0.27 & $323^{\mathrm{c}}$ & $15 \cdot 2$ & $535^{\mathrm{d}}$ & 37.3 & $511^{d}$ & $22 \cdot 4$ & $5 \cdot 70^{\mathrm{a}}$ & 0.41 & $205^{\mathrm{b}}$ & $12 \cdot 8$ & $524^{d}$ & 30.7 & $469^{d}$ & 33.6 \\
\hline GPx1 mRNA (fold of C15) & $1.00^{\mathrm{a}}$ & 0.22 & $4.37^{\mathrm{b}}$ & 0.36 & $5.48^{\mathrm{b}}$ & 1.02 & $4.57^{\mathrm{b}}$ & 0.57 & $1.03^{\mathrm{a}}$ & 0.24 & $5.00^{\mathrm{b}}$ & 0.35 & $5.42^{\mathrm{b}}$ & 0.68 & $5 \cdot 39^{\mathrm{b}}$ & 0.85 \\
\hline GSTA2 mRNA (fold of C15) & $1.00^{\mathrm{a}}$ & 0.08 & $0.47^{b, d}$ & 0.03 & $0.68^{\mathrm{c}}$ & 0.04 & $0.57^{b, c}$ & 0.03 & $0.91^{\mathrm{a}}$ & 0.05 & $0.47^{b, d}$ & 0.04 & $0.57^{b, c}$ & 0.05 & $0.36^{\mathrm{d}}$ & 0.05 \\
\hline Total GSH (nmol/mg prot.) & $69 \cdot 4^{\mathrm{a}, \mathrm{e}}$ & $2 \cdot 86$ & $64 \cdot 3^{\mathrm{a}, \mathrm{b}}$ & 2.03 & $61.5^{\mathrm{b}}$ & 3.35 & $61 \cdot 4^{\mathrm{b}}$ & 2.48 & $91 \cdot 0^{f}$ & 5.94 & $82 \cdot 2^{\mathrm{c}}$ & $3 \cdot 12$ & $72 \cdot 8^{\mathrm{d}, \mathrm{e}}$ & 3.52 & $72 \cdot 6^{\mathrm{d}, \mathrm{e}}$ & $2 \cdot 23$ \\
\hline Total HCys (nmol/mg prot.) & $91 \cdot 0^{\mathrm{a}}$ & 4.75 & $76 \cdot 2^{b}$ & 3.94 & $58 \cdot 4^{\mathrm{C}}$ & 5.35 & $55 \cdot 3^{\mathrm{c}}$ & $9 \cdot 85$ & $85 \cdot 5^{a, b}$ & $10 \cdot 9$ & $59 \cdot 6^{\mathrm{c}}$ & $4 \cdot 31$ & $54 \cdot 5^{\mathrm{c}}$ & $6 \cdot 19$ & $51 \cdot 4^{c}$ & 3.86 \\
\hline \multicolumn{17}{|l|}{ Plasma } \\
\hline $\mathrm{Se}(\mathrm{nmol} / \mathrm{ml})$ & $1.06^{a}$ & 0.12 & $26 \cdot 9^{\mathrm{c}}$ & 0.30 & $38.5^{\mathrm{d}}$ & 0.65 & $52 \cdot 4^{\mathrm{e}}$ & 0.55 & $1.87^{\mathrm{b}}$ & 0.09 & $27 \cdot 6^{\mathrm{c}}$ & 0.26 & $40 \cdot 6^{\mathrm{d}}$ & 0.73 & $52 \cdot 8^{\mathrm{e}}$ & 0.57 \\
\hline GPx3 activity (mU/mg prot.) & $4 \cdot 22^{a}$ & 0.46 & $88 \cdot 2^{\mathrm{b}}$ & 2.40 & $123^{\mathrm{d}}$ & $3 \cdot 26$ & $132^{\mathrm{d}, \mathrm{e}}$ & $5 \cdot 12$ & $4 \cdot 32^{\mathrm{a}}$ & 0.68 & $101^{\mathrm{c}}$ & 2.52 & $148^{\mathrm{e}}$ & 3.82 & $159^{\mathrm{e}}$ & 5.76 \\
\hline Total GSH $(\mu \mathrm{mol} / \mathrm{l})$ & $65 \cdot 9^{\mathrm{a}}$ & $2 \cdot 61$ & $51.0^{\mathrm{b}}$ & 1.90 & $48 \cdot 9^{b}$ & 2.79 & $39 \cdot 1^{\mathrm{c}, \mathrm{e}}$ & 1.03 & $53.0^{\mathrm{b}}$ & 7.55 & $38.4^{\mathrm{c}, \mathrm{e}}$ & $2 \cdot 18$ & $35 \cdot 3^{\mathrm{c}, \mathrm{e}, \mathrm{d}}$ & 1.51 & $32 \cdot 2^{\mathrm{d}}$ & 1.44 \\
\hline Total GSH (nmol/mg prot.) & $1 \cdot 12^{\mathrm{a}}$ & 0.06 & $0.87^{b}$ & 0.04 & $0 \cdot 82^{b}$ & 0.05 & $0.68^{\mathrm{c}}$ & 0.03 & $0.84^{\mathrm{b}}$ & 0.18 & $0.62^{\mathrm{c}, \mathrm{e}}$ & 0.05 & $0.57^{e, d}$ & 0.04 & $0.54^{d}$ & 0.04 \\
\hline Total HCys $(\mu \mathrm{mol} / \mathrm{l})$ & $6 \cdot 78^{a}$ & 0.23 & $12 \cdot 7^{\mathrm{b}}$ & 0.61 & $14 \cdot 0^{\mathrm{b}}$ & 0.76 & $13 \cdot 6^{\mathrm{b}}$ & 0.46 & $12 \cdot 0^{\mathrm{b}}$ & $2 \cdot 17$ & $23 \cdot 4^{\mathrm{d}}$ & 1.68 & $23 \cdot 2^{d}$ & $2 \cdot 47$ & $18 \cdot 6^{\mathrm{c}}$ & 1.61 \\
\hline Total HCys (nmol/mg prot.) & $0.12^{\mathrm{a}}$ & 0.01 & $0.22^{\mathrm{b}}$ & 0.02 & $0.23^{b}$ & 0.03 & $0.24^{\mathrm{b}}$ & 0.02 & $0.22^{b}$ & 0.08 & $0.38^{d}$ & 0.06 & $0.37^{d}$ & 0.07 & $0.31^{\mathrm{c}}$ & 0.06 \\
\hline \multicolumn{17}{|l|}{ Liver + plasma } \\
\hline GSH (nmol/mg prot.) & $70 \cdot 5^{a}$ & 1.46 & $65 \cdot 2^{\mathrm{b}}$ & 1.04 & $62 \cdot 3^{\mathrm{b}}$ & 1.70 & $62 \cdot 1^{\mathrm{b}}$ & 1.25 & $91 \cdot 8^{\mathrm{c}}$ & 3.06 & $82 \cdot 8^{\mathrm{d}}$ & 1.59 & $73.4^{e}$ & 1.78 & $73.1^{\mathrm{e}}$ & $1 \cdot 13$ \\
\hline HCys (nmol/mg prot.) & $91 \cdot 1^{\mathrm{a}}$ & $2 \cdot 38$ & $76 \cdot 4^{\mathrm{b}}$ & 1.98 & $58 \cdot 6^{\mathrm{C}}$ & $2 \cdot 68$ & $55 \cdot 5^{\mathrm{C}}$ & 4.93 & $85 \cdot 7^{\mathrm{a}}$ & 5.47 & $59.9^{\mathrm{c}}$ & $2 \cdot 17$ & $54.9^{c}$ & 3.11 & $51 \cdot 7^{\mathrm{C}}$ & 1.94 \\
\hline
\end{tabular}

\section{prot., Protein.}

ean values within a row with unlike superscript letters were significantly different $(P<0.05)$

${ }^{*}$ For details of diets and procedures, see Methods and materials. 
mRNA expression of key enzymes of homocysteine and glutathione metabolism

To investigate the molecular causes underlying the present results for liver and plasma GSH and HCys concentrations, we analysed the mRNA expression of the key enzymes of GSH and HCys metabolism in the liver of the rats (Fig. 1(a)-(g)). Glycine- $N$-methyltransferase expression was affected neither by the dietary Se concentration nor by the dietary Met level (Fig. 1(a)). In the $\mathrm{C}$ groups with the recommended dietary Met concentration, liver CBS expression in the Se-supplemented rats was $38-43 \%$ lower than that in the Se-deficient group. However, no significant differences in CBS gene expression occurred between rats with different dietary Se supplementations (C50, C150 and C450). The high Met concentration in the diet did not significantly change the CBS expression level in the Se-deficient group M15 compared with group C15. In Se-supplemented rats fed the high Met diet, CBS expression was further reduced to $22-35 \%$ of that in $\mathrm{C} 15$ rats $(17-30 \%$ of that in M15 rats). Thus, Se-supplemented rats with high Met diets (M50,

(a)

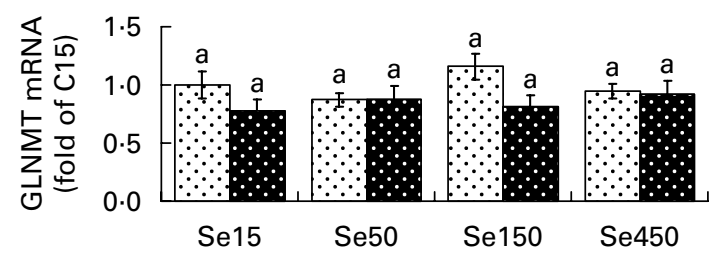

(b)

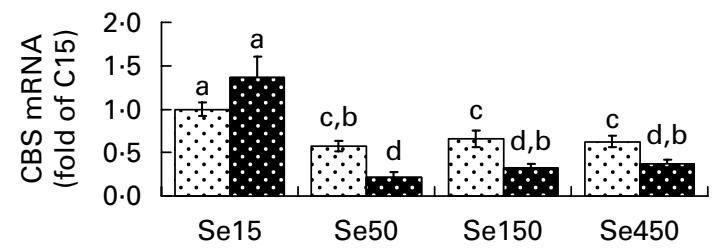

(c)

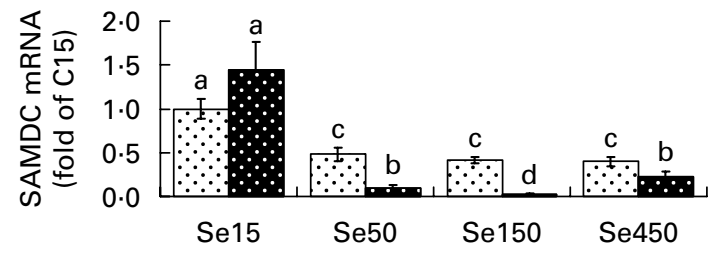

M150 and M450) had in each case a significantly lower liver CBS expression than groups C50, C150 and C450 (Fig. 1(b)). A very similar expression profile as analysed for CBS could also be observed for liver $S$-adenosylmethionine decarboxylase expression. $S$-adenosylmethionine decarboxylase expression in the Se-supplemented rats was reduced to approximately $40 \%$ (C groups) and 5-20\% (M groups) of that measured in their respective Se-deficient companions in groups $\mathrm{C} 15$ and M15 (Fig. 1(c)). In the C groups, BHMT responsible for betaine-dependent remethylation of HCys to Met was increased in the Se-supplemented groups C50, C150 and C450 up to 1.6-fold compared with group C15. With the exception of groups C150 and M150, BHMT expression was slightly but not significantly higher in all $\mathrm{M}$ groups compared with their respective $\mathrm{C}$ groups (Fig. 1(d)). The key enzymes of the GSH biosynthesis pathway were also strongly influenced by the dietary Se and Met concentrations. The expression of the GCLM was reduced by Se supplementation to $30-60 \%$ of that in the Se-deficient rats (C15 and M15), with the lowest expression in group M450

(d)

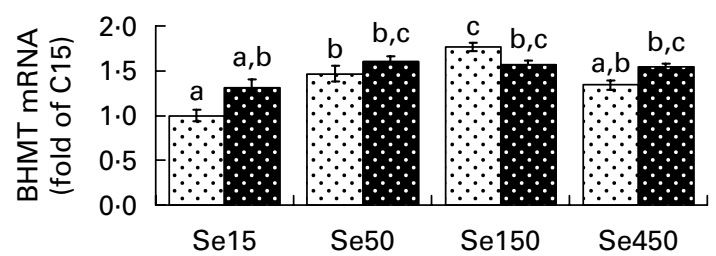

(e)

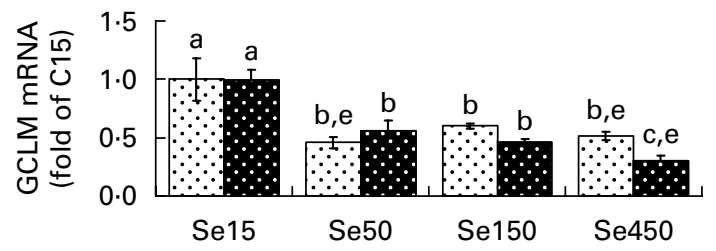

(f)

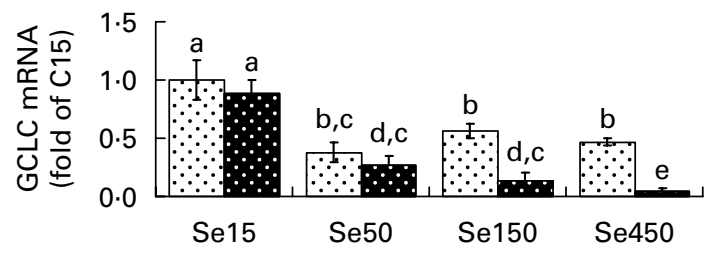

(g)

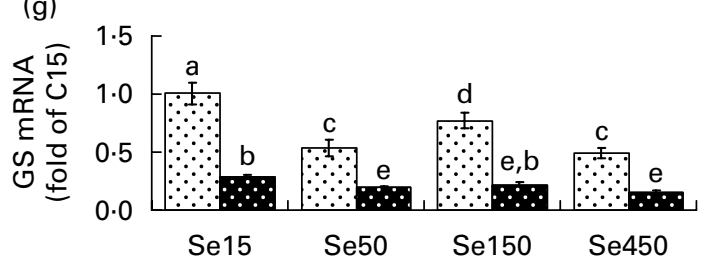

Fig. 1. (a)-(g) mRNA expression of the key enzymes of homocysteine metabolism ((a)-(d)) and GSH metabolism ((e)-(g)) of rats fed diets containing different dietary concentrations in combination with two dietary methionine levels (values are means with their standard errors). ${ }^{a, b, c, d, e}$ Mean values with unlike letters were significantly different $(P<0.05)$. $n 8$ animals are considered. For details of diets and procedures, see Methods and materials. GLNMT, glycine- $N$-methyltransferase; CBS, cystathione- $\beta$-synthase; SAMDC, S-adenosylmethionine decarboxylase; BHMT, betaine hydroxymethyltransferase; GCLM, glutamate cysteine ligase, modulatory subunit; GCLC, glutamate cysteine ligase, catalytic subunit; GS, glutathione synthetase. (a) -(g) $\square$, C groups; $\mathbf{B}, \mathrm{M}$ groups. 
(Fig. 1(e)). In contrast to the expression of GCLM, the expression of the GCLC was in addition strongly regulated by the dietary Met concentration. Whereas the expression of liver GCLC in the C groups was reduced to $40-55 \%$ of that in Se-deficient $\mathrm{C} 15$ rats by Se supplementation at all the dietary levels investigated (C50, C150 and C450), the expression of the enzyme in the Se-supplemented groups with high dietary Met (M50, M150 and M450) was reduced to $4-27 \%$ of that in $\mathrm{C} 15$ rats and to $5-30 \%$ of that in M15 rats. Moreover, in Se-supplemented high Met rats of groups M50, M150 and M450, a significant influence of the dietary Se concentration on GCLC expression could be analysed (Fig. 1(f)). GS expression in the liver was the highest in the Se-deficient $\mathrm{C} 15$ rats. Independent of the Se concentration in groups $\mathrm{C} 50, \mathrm{C} 150$ and $\mathrm{C} 450$, a reduction of GS expression to $50-70 \%$ of the level in group C15 was analysed. The addition of the higher Met level to the diets drastically reduced GS expression. Thus, in M15 rats, GS expression was only $30 \%$ of that in $\mathrm{C} 15$ rats (Fig. $1(\mathrm{~g})$ ).

Cholesterol concentration in the liver and plasma, and $m R N A$ expression of genes involved in the regulation of cholesterol metabolism

Both Se-deficient groups (C15 and M15) had a 18-27\% (C groups) and a 37-44\% (M groups) lower liver Chol concentration than the respective Se-supplemented groups C50, C150, C450, M50, M150 and M450 (Table 4). At both dietary Met concentrations, the rats with the highest dietary Se supplementation of $450 \mu \mathrm{g} / \mathrm{kg}$ (C450 and M450) had a slightly higher liver Chol concentration than the other Se-supplemented groups. However, at the same dietary Met level, no significant differences in the liver Chol level existed between the Sesupplemented groups. With the exception of the Se-deficient groups C15 and M15 and groups C50 and M50, the Sesupplemented groups M150 and M450 had a significantly higher liver Chol concentration than their companions in groups $\mathrm{C} 150$ and $\mathrm{C} 450$ receiving diets with the recommended dietary Met concentration. In contrast to the liver Chol concentration at both dietary Met levels, plasma Chol concentration in the Se-supplemented groups C50, C150, C450, M50, M150 and M450 was $15-25 \%$ lower than that in the Se-deficient groups. The gene expression of enzymes involved in the regulation of whole body Chol metabolism showed a differential expression pattern (Table 4). No significant differences in gene expression could be analysed for the transcription factor SREBP2 between all the experimental groups. The expression of HMGCoAR was also not affected by the different dietary conditions. The expression of liver LDLR was the lowest in group C15 with Se deficiency and the recommended dietary Met level. All the Se-supplemented rats receiving diets with the recommended dietary Met concentration (C50, 150 and C450) had an approximately $2 \cdot 5$-fold higher expression of liver LDLR than the C15 rats. The rats of the $M$ groups had a $1 \cdot 5$ - to $2 \cdot 0$-fold higher expression of liver LDLR than their companions in the respective $\mathrm{C}$ groups (M15 v. C15, M50 v. C50, M150 v. $\mathrm{C} 150$ and M450 v. C450). The hepatobiliary Chol exporter ABCG8 showed the highest expression level in the Sedeficient M15 rats. The second highest expression was analysed in the corresponding Se-deficient C15 group fed

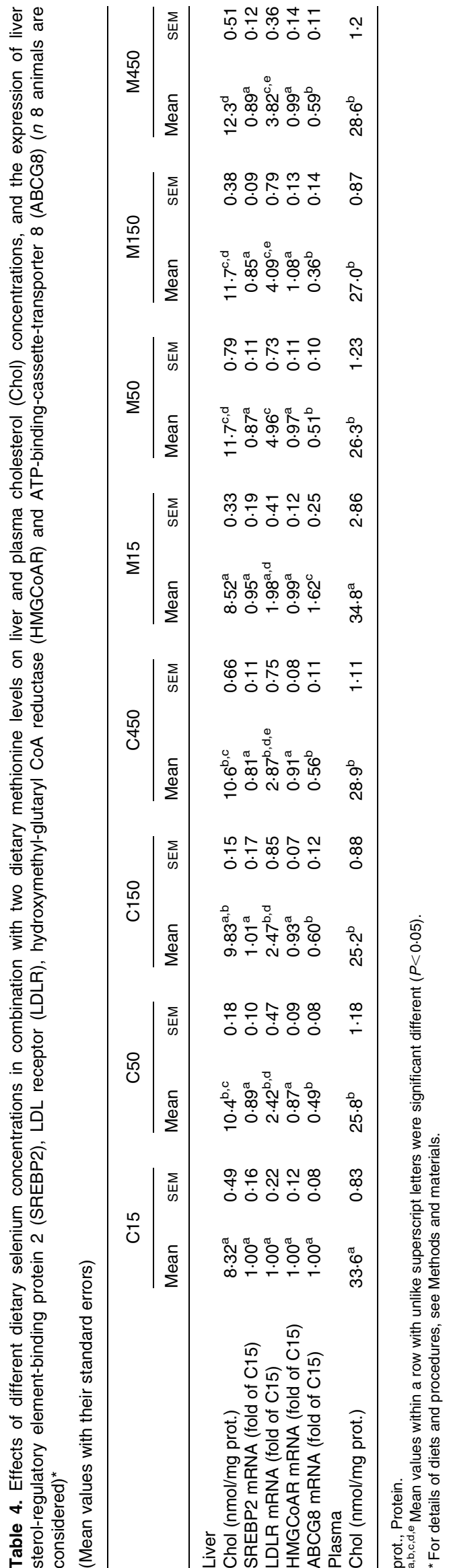


diets containing the recommended dietary Met level. Se supplementation reduced the expression of ABCG8 to approximately 50\% (groups C50, C150 and C450) and $30 \%$ (groups M50, M150 and M450) of the level in the corresponding Se-deficient groups C15 and M15.

\section{Discussion}

\section{Rat performance parameters and selenium status}

In the present study, we investigated for the first time the combined effect of four dietary Se concentrations and two Met concentrations on the metabolism of HCys and Chol in rats. In accordance with our previous studies with rats on the effects of Se on the regulation of protein tyrosine phosphatase-1B and TAG metabolism ${ }^{(45,46)}$, our current data confirm a reduced feed conversion of Se-deficient rats at both dietary Met levels tested. With regard to Met and HCys metabolism, other dietary factors (e.g. folate, vitamin $\mathrm{B}_{12}$ and choline) influencing these pathways remained constant in the present experiment. The parameters of Se status (liver and plasma Se, liver GPx1 and plasma GPx3) confirm that the basal diets C15 and M15 produced a marked Se deficiency, and that the graded amounts of Se added to the other diets led to a stepwise increase in liver and plasma Se concentrations. However, the plateau in GPx1 expression and activity as well as in GPx3 activity was definitely reached with the recommended dietary Se level of $150 \mu \mathrm{g} / \mathrm{kg}^{(47,48)}$. The phase II enzyme glutathione $S$-transferase $\alpha 2$, another sensitive indicator of Se deficiency, also indicated Se-deficient conditions of groups C15 and M15 by its higher expression in Se deficiency $^{(48)}$.

\section{Influence of selenium and methionine on GSH and homocysteine metabolism}

In accordance with studies on rats investigating the influence of Se status on HCys metabolism ${ }^{(18-20)}$, we also found a doubling of total plasma HCys concentration in the Sesupplemented groups at both dietary Met levels compared with the respective Se-deficient groups C15 and M15. An interesting finding of the present study is that the addition of $15 \mathrm{~g} \mathrm{Met} / \mathrm{kg}$ diet (M15, M50, M150 and M450) again doubled plasma HCys concentration compared with the respective groups with the recommended dietary Met amount (C15, $\mathrm{C} 50, \mathrm{C} 150$ and $\mathrm{C} 450$ ). In this context, it is noteworthy that the HCys ratio between Se-deficient rats (C15 and M15) and Se-supplemented rats of the respective dietary Met level remained nearly constant at 1:2. The fact that dietary Met concentration is an important factor that influences plasma $\mathrm{HCys}$ concentration was reported for rats as well as for human subjects through an increased dietary Met intake by the consumption of a high protein diet, or subjected to oral Met loading ${ }^{(28,29,32,34)}$. The inclusion of two dietary Met levels in our experimental design, the measurement of liver and plasma HCys and GSH concentrations, and the measurement of the expression of an increased spectrum of the key enzymes of HCys and GSH homoeostasis contribute to an improved understanding of HCys metabolism in rats (Table 2 and Fig. 1). In these studies, the main conclusion explaining the higher plasma HCys concentration was deduced from the fact that Se-deficient rats had a higher expression and activity of the key enzymes of the GSH biosynthesis pathway in the liver (confirmed in the present study by GCLM, GCLC and GS expression) than their Se-supplemented companions, leading to a 'pull' on transsulphuration, and consequently, to lower plasma HCys levels in Se-deficient rats. However, in these studies, liver HCys concentration was not analysed ${ }^{(18,20,21)}$. Additional analysis of glycine- $N$-methyltransferase expression (not influenced by $\mathrm{Se}$ status and dietary Met level), CBS expression (strongly reduced in Se-supplemented $\mathrm{C}$ and $\mathrm{M}$ groups compared with the Se-deficient C15 and M15 rats) and BHMT expression (slightly increased in Se-supplemented $\mathrm{C}$ and $\mathrm{M}$ rats compared with their Se-deficient companions) and of the liver HCys concentration (reduced by Se supplementation in $\mathrm{C}$ and $\mathrm{M}$ rats) in the present study gives rise to some new hypotheses regarding the regulation of the HCys metabolism in rats. In comparison to previous studies on rat GSH or HCys metabolism, the present results suggest the following analogies and new aspects:

(1) In accordance with previous work on rat GSH and HCys metabolism $^{(18-21,49-51)}$, our data confirmed that both the plasma and liver GSH concentrations were increased in Se deficiency, and may result from a pull on the transsulphuration pathway (liver GSH) and a higher export into the plasma (plasma GSH). In these earlier studies, plasma GSH values in Se-deficient rats were nearly twofold increased compared with controls with adequate Se supply ${ }^{(49,50)}$. In the present experiment at both dietary Met concentrations, the reduction of plasma GSH values to half of that in the Se-deficient groups was obtained with a Se supplementation of $450 \mu \mathrm{g} / \mathrm{kg}$ (groups C450 and M450). The increased expression levels of CBS as well as of GCLC, GCLM and GS in Se deficiency support these findings.

(2) Contrary to expectations, the highest expression of CBS in the Se-deficient groups C15 and M15 and almost unchanged expression levels of glycine- $N$-methyltransferase and BHMT compared with the Se-supplemented groups produced the highest liver HCys concentrations. Therefore, this effect seems to be the consequence of a higher liver HCys disposal under Se-deficient conditions and an increased HCys export into the plasma by Se supplementation and particularly by a higher dietary Met intake rather than deriving from the reduction of the key enzymes of GSH biosynthesis. The dependency of HCys export into the plasma on dietary Met concentration was impressively demonstrated in a rat study ${ }^{(52)}$.

(3) However, in rats, the Se-dependent manipulation of HCys export into the plasma only responds to switching over from Se deficiency to Se supply. A further increase in plasma HCys concentration due to an increase in dietary Se supplementation and plasma Se values cannot be observed. This particular aspect may explain the contradictory results for the interaction of $\mathrm{Se}$ status and plasma HCys level in rats $^{(18-21)}$ and human subjects ${ }^{(22-27)}$, since in none of the human studies was a group with severe Se deficiency included. However, in the human studies, in which an inverse relationship between plasma Se and plasma HCys has been identified, the groups with an increased plasma HCys concentration 
had very low plasma Se values $(0 \cdot 56-0.79 \mu \mathrm{mol} / \mathrm{l})^{(22-25)}$ than those in the studies in which Se status or Se supplementation remained without an effect on plasma HCys concentration $(>1.0 \mu \mathrm{mol} / \mathrm{l})^{(26,27)}$. In this context, it is of interest that the summation of plasma and liver HCys concentrations from the present experiment leads to an inverse relationship between Se status and the summated HCys concentration (Table 2). Moreover, independent of the dietary Met concentration, nearly identical summated HCys concentrations can be observed for the different dietary Se concentrations (C15 v. M15, C50v. M50, C150 v. M150 and C450 v. M150) (Table 2). Thus, future investigations into the influence of Se, Met or other nutrients on HCys metabolism should consider species differences in hepatic HCys export, and investigate the influence of nutrients on specific carriers involved in HCys export ${ }^{(53)}$.

(4) Another interesting finding of the present study is that it was not only liver HCys disposal that was reduced by Se and Met. The Se- and above all Met-dependent distinct down-regulation of the polyamine-synthesising enzyme $S$-adenosylmethionine decarboxylase seems to have a protective function for the organism since polyamines are discussed as being involved in the generation of a number of diseases from cancer and psoriasis to parasitic infections ${ }^{(54)}$.

\section{Influence of selenium and methionine on cholesterol metabolism}

In the present study, we also aimed to elucidate the molecular links between the amount of dietary Se and Met supplementation and Chol metabolism. In the literature, there exists inconsistent information on the effects of both nutrients on Chol metabolism. Thus, for Se, a large recent US crosssectional observational trial with 7129 participants reported a distinct positive correlation between serum Se concentration and serum Chol levels. In the present study, participants in the top quartile (serum $\mathrm{Se}>1.70 \mu \mathrm{mol} / \mathrm{l}$ ) had $8 \%$ higher serum Chol levels, $8 \%$ higher LDL Chol levels and $5 \%$ higher HDL Chol levels than participants in the bottom quartile (serum Se $<1.43 \mu \mathrm{mol} / 1)^{(35)}$. The data of a very recent cross-sectional observational trial from the $\mathrm{UK}^{(36)}$ including 1042 white female and male adults aged 19-64 years confirm the findings of the above-mentioned US study. Despite the overall somewhat lower plasma Se concentrations (bottom quartile: $<0.98 \mu \mathrm{mol} / 1$, top quartile: $1.20-2.79 \mu \mathrm{mol} / \mathrm{l}) \mathrm{com}-$ pared with the US study, the participants of the top quartile had $11 \%$ higher total plasma Chol values and $12 \%$ higher LDL Chol values than those in the bottom quartile ${ }^{(35,36)}$. Another study from Lebanon confirms these results. A higher Se status correlated significantly and positively with a number of markers of the metabolic syndrome including plasma $\mathrm{Chol}^{(55)}$. In contrast, a study from Japan in pre- and postmenopausal women found a decrease of Se status and an increase in plasma Chol level after menopause, and suggested a beneficial effect of Se supplements in lowering Chol values $^{(56)}$. Several studies with rats with a dietary induced hypercholesterolaemia found that Se supplementation with $1.0 \mathrm{mg} / \mathrm{kg}$ diet clearly reverses hypercholesterolaemia by lowering liver apo B and HMGCoAR expression and by increasing LDLR expression ${ }^{(57-59)}$. A similarly unclear effect as found for Se on Chol metabolism also exists for Met and HCys on Chol metabolism.

In this context, a hypothesis report ${ }^{(60)}$ and a study with transgenic mice ${ }^{(61)}$ suggest that a high dietary Met concentration increases the need for phosphatidylethanolamine (PE)- $N$-methyltransferase for the formation of HCys. Through this increased use of PE- $N$-methyltransferase for HCys metabolism, the reaction actually catalysed by the enzyme, namely the conversion of PE to phosphatidylcholine, is decelerated. Phosphatidylcholine is again an important phospholipid for the formation of VLDL particles. Therefore, high Met and HCys may increase lipid storage in the liver, and contribute to the development of non-alcoholic fatty liver disease. Moreover, high HCys concentrations may lower liver HDL synthesis, and therefore reduce reverse Chol transport ${ }^{(60)}$. A study with transgenic PE- $N$-methyltransferase $-/-$ mice showed that these animals had a reduced liver VLDL secretion than their PE- $N$-methyltransferase $+/+$ companions $^{(61)}$. Accordingly, Met loading in the elderly led to a fourfold increase in plasma HCys concentration and a $22.5 \%$ increase in total Chol:HDL ratio in the plasma ${ }^{(34)}$. In a study with growing rats, the gradual increase of the dietary Met concentration from 2.6 to $6.0 \mathrm{~g} / \mathrm{kg}$ diet led to the stepwise increase in plasma HCys and in both plasma and liver Chol. In the present study, the most distinct increase in plasma and liver Chol was analysed between rats consuming the low Met diet $(2.6 \mathrm{~g} / \mathrm{kg})$ and rats fed the next higher dietary Met level of $3.5 \mathrm{Met} / \mathrm{kg}$ diet. A by far lower and NS increase in plasma and liver Chol was observed between rats consuming the other diets containing up to $6.0 \mathrm{~g} \mathrm{Met} / \mathrm{kg}$ diet. An increased expression of the SREBP2 and of HMGCoAR was analysed as the molecular cause for the increasing effect of Met/HCys on liver and plasma Chol. However, the expression of the liver LDLR, another target gene of SREBP2, showed no response to the different Met concentrations ${ }^{(29)}$. In another study with tissue cultures and mice, it was postulated that the increased liver Chol synthesis by HCys derives from the activation of lipogenic SREBP transcription factors and VLDL secretion by endoplasmatic reticulum stress ${ }^{(62)}$. In contrast to the above-mentioned studies, describing a Chol-increasing effect of Met supplementation to diets, Chol-lowering effects of Met have also been investigated. Thus, in a rat study, the addition of $3.0 \mathrm{~g} \mathrm{Met} / \mathrm{kg}$ to a $10 \%$ soya protein diet effected a $40 \%$ reduction of plasma Chol, whereas the Met addition to a $20 \%$ soya protein diet effected a small and NS increase in plasma Chol. A significant reduction of liver HMGCoAR activity and a significant increase in Chol-7- $\alpha$-hydroxylase activity, the key enzyme for bile acid synthesis, were analysed as the molecular causes for the Chol-lowering effect of $\mathrm{Met}^{(63)}$. In another study, rats with an implanted ascites hepatoma cell line developed severe hypercholesterolaemia, based on the reduction of bile acid excretion. Met addition to the diets restored Chol metabolism by increasing Chol excretion via the bile ${ }^{(64)}$.

The comparison of our data with the data from the above-mentioned studies on the role of $\mathrm{Se}$ and Met in Chol metabolism indicates both analogies and inconsistencies. In accordance with the studies in which hypercholesterolaemia in rats was induced by feeding high Chol diets, our data 
confirm the up-regulation of the liver LDLR and the decrease of plasma Chol by Se. In contrast to these studies, we could not find a reduction of HMGCoAR expression by Se. This difference may result from a higher Chol loading of the livers in the cited studies by feeding of high Chol diets in combination with an up-regulated LDLR. However, liver Chol data were not provided in these studies ${ }^{(57-59)}$. When the free liver Chol concentration exceeds a critical value, the processing of the transcription factor SREBP2 by the SREBP cleavage-activating protein is blocked via an up-regulation of the insulin-induced genes 1 and 2 (Insig 1 and 2) which bind to SREBP cleavage-activating protein $^{(65)}$. Despite significantly higher liver Chol concentrations in the Se-supplemented $\mathrm{C}$ and $\mathrm{M}$ groups than in the respective Se-deficient groups, the feeding of Chol-free diets in the present study obviously did not result in a liver Chol concentration switching on the Insig-SREBP cleavage-activating protein-SREBP2 system. In this context, it should be mentioned that we could not detect any differences in the expression of Insig 1 and 2 (data not presented). A further new result in the present study was the finding that the hepatobiliary Chol exporter ABCG8, which also plays an important role in the reverse transport of phytosterols into the lumen of the small intestine ${ }^{(66,67)}$, was distinctly down-regulated in all Se-supplemented rats, and therefore provides a further explanation for the higher Chol concentration in the livers of Se-supplemented rats and for their lower plasma Chol levels. In contrast to the previous rat studies ${ }^{(57-59)}$ and to the present results, recent human studies found a positive correlation between a high Se status and an increased plasma Chol concentration ${ }^{(35,36)}$. One possible explanation for this difference is the fact that in the rat studies, young and still growing animals were used, whereas the human data were collected from adults. This fact raises the question whether the long-term uptake of Se above the recommendations via permanent Chol accumulation in the liver would ultimately also increase plasma Chol values. Thus, long-term studies with rats or better with pigs, which have a lipoprotein metabolism which is more closely related to that of human subjects, are needed to confirm or confute the risk of Se supplementation for increased plasma Chol values. In accordance with previous rat studies ${ }^{(29,68)}$, in the present study, a positive and significant correlation also existed between the dietary Met level and the liver Chol concentration. However, in contrast to these studies ${ }^{(29,68)}$ and to the human study ${ }^{(34)}$ examining the effect of Met loading on Chol metabolism, we could not find a significant increase in plasma Chol concentration by increasing the dietary Met concentration to fivefold of the recommended amount. Similarly as discussed for Se, it is conceivable that feeding adult rats a high Met diet in combination with Chol addition to the diet also increases plasma Chol concentration. However, the present results showing the up-regulation of the LDLR by Se and Met and the additional down-regulation of ABCG8 by Se suggest that the over-supplementation with both nutrients may rather increase the risk of the early development of non-alcoholic fatty liver disease. Another very interesting issue regarding ABCG8 regulation which should be examined in the future involves the function of this transporter in the small intestine where it is selectively involved in the reverse transport of phytosterols but not of Chol back into the lumen. In the case of a phytosterol-rich diet, this particular aspect would suggest a positive influence of a high Se status on plasma Chol level, since a reduced export of phytosterols back to the intestinal lumen would lead to a replacement of Chol by phytosterols.

\section{Conclusions}

The present rat study investigating the combined effects of Se and Met on HCys and Chol metabolism reveals the following new aspects:

(1) Se increases plasma HCys concentration only when Se-deficient conditions are compared with Se supplementation, independent of the dietary Met concentration. Already at a suboptimal Se supply of $50 \mu \mathrm{g} / \mathrm{kg}$ diet, the plasma HCys level reaches a plateau concentration. When compared with Se-deficient conditions, the elevation of plasma HCys level by dietary Se does not only result from the reduction of the liver key enzymes of GSH biosynthesis and the subsequent deceleration of the transsulphuration pathway. Se also reduces liver HCys disposal by an increased export into the plasma. Due to the fact that plasma HCys concentration can only be reduced by severe Se deficiency, which is not desirable in human subjects, in our opinion, it can be assumed that Se supplementation is not clearly a risk factor for homocysteinaemia in human subjects. Moreover, our rat model suggests that the summation of plasma and liver HCys concentration results in an inverse relationship between Se status and the HCys concentration, as was similarly reported from some human trials. A high dietary Met concentration, however, is a substantial risk factor for homocysteinaemia. In summary, the rat, in particular when fed diets with a high Met concentration and sufficient Se, may represent a useful model for further critical study of the controversial role of HCys as a risk factor for atherosclerosis, CVD and ischaemic stroke.

(2) Se increases liver Chol via two mechanisms, the concentration-dependent up-regulation of the liver LDLR and the down-regulation of the hepatobiliary Chol exporter ABCG8. A high dietary Met concentration amplifies the Se effects on liver Chol concentration. The present results do not support the findings from recent human trials in which a high Se status corresponded to elevated levels of total Chol and LDL Chol in plasma, but point rather to the development of non-alcoholic fatty liver disease by the long-term over-supplementation with Se and Met.

However, future investigations with animal models should examine the effects of Se supplementation on Chol metabolism when diets with a high energy and Chol concentration are consumed, as is the case in industrial nations. In this context, the role of phytosterols should also be addressed. Furthermore, the pig may represent a better animal model for future studies on Se and Chol metabolism, since its lipoprotein metabolism is more closely related to that of human subjects than to that of the rat.

\section{Acknowledgements}

All the authors declare that they have no conflicts of interest, and that they have significantly contributed to the paper. 
The present research received no specific grant from any funding agency in the public, commercial or not-for-profit sectors. N. M. W. conducted the rat study, prepared the samples, and participated in the analyses of HCys, GSH and enzymes. She was further involved in statistical data analysis and in writing of the manuscript. K. M. carried out RNA extraction and reverse transcription, and supervised real-time PCR experiments. Moreover, she evaluated the real-time PCR data. F. H. supervised HCys and GSH analyses, and evaluated the relevant data. E. M. supervised Se analysis and evaluated the relevant data. J. P. provided laboratory support at the Justus Liebig University of Giessen for the rat nutrition trial and for some of the analyses. He also helped in compiling the manuscript. A. S. M. designed the study, was involved in the gene expression analyses, checked the statistical evaluation, prepared the tables and figures, and has written large passages of the manuscript. We thank our Masters students Doris Lippmann and Anne Cathrin Seltmann for their help with analyses within the scope of their Masters theses.

\section{References}

1. Zhou J \& Austin RC (2009) Contributions of hyperhomocysteinemia to atherosclerosis: causal relationship and potential mechanisms. Biofactors 35, 120-129.

2. Lin CP, Chen YH, Chen JW, et al. (2008) Cholestin (Monascus purpureus rice) inhibits homocysteine-induced reactive oxygen species generation, nuclear factor-kappaB activation, and vascular cell adhesion molecule-1 expression in human aortic endothelial cells. J Biomed Sci 15, 183-196.

3. Kassab A, Ajmi T, Issaoui M, et al. (2008) Homocysteine enhances LDL fatty acid peroxidation, promoting microalbuminuria in type 2 diabetes. Ann Clin Biochem 45, 476-480.

4. Séguin C, Abid MR, Spokes KC, et al. (2008) Priming effect of homocysteine on inducible vascular cell adhesion molecule-1 expression in endothelial cells. Biomed Pharmacother 62, 395-400.

5. Au-Yeung KK, Woo CW, Sung FL, et al. (2004) Hyperhomocysteinemia activates nuclear factor-kappaB in endothelial cells via oxidative stress. Circ Res 94, 28-36.

6. Ungvari Z, Csiszar A, Edwards JG, et al. (2003) Increased superoxide production in coronary arteries in hyperhomocysteinemia: role of tumor necrosis factor-alpha, NAD $(\mathrm{P}) \mathrm{H}$ oxidase, and inducible nitric oxide synthase. Arterioscler Thromb Vasc Biol 23, 418-424.

7. Griffiths HR, Aldred S, Dale C, et al. (2006) Homocysteine from endothelial cells promotes LDL nitration and scavenger receptor uptake. Free Radic Biol Med 40, 488-500.

8. Flicker L (2009) Life style interventions to reduce the risk of dementia. Maturitas 63, 319-322.

9. Bønaa KH, Njølstad I, Ueland PM, et al. (2006) Homocysteine lowering and cardiovascular events after acute myocardial infarction. N Engl J Med 354, 1578-1588.

10. Antoniades C, Antonopoulos AS, Tousoulis D, et al. (2009) Homocysteine and coronary atherosclerosis: from folate fortification to the recent clinical trials. Eur Heart J 30, 6-15.

11. Lonn E, Yusuf S, Arnold MJ, et al. (2006) Homocysteine lowering with folic acid and B vitamins in vascular disease. $N$ Engl J Med 354, 1567-1577.

12. Malinow MR, Bostom AG, Krauss RM, et al. (1999) Homocyst(e)ine, diet, and cardiovascular diseases: a statement for healthcare professionals from the Nutrition Committee, American Heart Association. Circulation 99, 178-182.
13. Stanger O, Herrmann W, Pietrzik K, et al. (2003) DACH-LIGA homocystein (German, Austrian and Swiss Homocysteine Society): consensus paper on the rational clinical use of homocysteine, folic acid and B-vitamins in cardiovascular and thrombotic diseases: guidelines and recommendations. Clin Chem Lab Med 41, 1392-1403. Review. Erratum in: Clin Chem Lab Med 2004; 42, 113-116.

14. Max Rubner-Institut, Bundesforschungsinstitut für Ernährung und Lebensmittel, Haid-und-Neu-Str. 976131 [Karlsruhe, editor].

15. Must A, Jacques PF, Rogers G, et al. (2003) Serum total homocysteine concentrations in children and adolescents: results from the third National Health and Nutrition Examination Survey (NHANES III). J Nutr 133, 2643-2649.

16. Heinz J, Kropf S, Luley C, et al. (2009) Homocysteine as a risk factor for cardiovascular disease in patients treated by dialysis: a meta-analysis. Am J Kidney Dis 54, 478-489.

17. Halpin KM \& Baker DH (1984) Selenium deficiency and transsulfuration in the chick. J Nutr 114, 606-612.

18. Uthus EO, Yokoi K \& Davis CD (2002) Selenium deficiency in Fisher-344 rats decreases plasma and tissue homocysteine concentrations and alters plasma homocysteine and Cys redox status. J Nutr 132, 1122-1128.

19. Uthus EO, Ross SA \& Davis CD (2007) Differential effects of dietary selenium (Se) and folate on methyl metabolism in liver and colon of rats. Biol Trace Elem Res 109, 201-214.

20. Uthus EO \& Ross SA (2007) Dietary selenium affects homocysteine metabolism differently in Fisher-344 rats and CD-1 mice. J Nutr 137, 1132-1136.

21. Uthus EO \& Ross SA (2009) Dietary selenium (Se) and copper $(\mathrm{Cu})$ interact to affect homocysteine metabolism in rats. Biol Trace Elem Res 129, 213-220.

22. González S, Huerta JM, Alvarez-Uría J, et al. (2004) Serum selenium is associated with plasma homocysteine concentrations in elderly humans. J Nutr 134, 1736-1740.

23. Klapcińska B, Poprzęcki S, Danch A, et al. (2005) Selenium levels in blood of upper Silesian population: evidence of suboptimal selenium status in a significant percentage of the population. Biol Trace Elem Res 108, 1-15.

24. Bates CJ, Thane CW, Prentice A, et al. (2002) Selenium status and its correlates in a British national diet and nutrition survey: people aged 65 years and over. J Trace Elem Med Biol 16, $1-18$.

25. Bélanger MC, Dewailly E, Berthiaume L, et al. (2006) Dietary contaminants and oxidative stress in Inuit of Nunavik. Metabolism 55, 989-995.

26. Venn BJ, Grant AM, Thomson CD, et al. (2008) Selenium supplements do not increase plasma total homocysteine concentrations in men and women. $J$ Nutr 133, 418-420.

27. Bekaert B, Cooper ML, Green FR, et al. (2008) Effect of selenium status and supplementation with high-selenium yeast on plasma homocysteine and B vitamin concentrations in the UK elderly. Mol Nutr Food Res 52, 1324-1333.

28. Hirche F, Schröder A, Knoth B, et al. (2006) Met-induced elevation of plasma homocysteine concentration is associated with an increase of plasma cholesterol in adult rats. Ann Nutr Metab 50, 139-146.

29. Hirche F, Schröder A, Knoth B, et al. (2006) Effect of dietary Met on plasma and liver cholesterol concentrations in rats and expression of hepatic genes involved in cholesterol metabolism. Br J Nutr 95, 879-888.

30. Ward M, McNulty H, Pentieva K, et al. (2000) Fluctuations in dietary Met intake do not alter plasma homocysteine concentration in healthy men. J Nutr 130, 2653-2657.

31. Ward M, McNulty H, McPartlin J, et al. (2001) Effect of supplemental Met on plasma homocysteine concentrations in healthy men: a preliminary study. Int J Vitam Nutr Res 71, 82-86. 
32. Verhoef $\mathrm{P}$, van Vliet T, Olthof MR, et al. (2005) A high-protein diet increases postprandial but not fasting plasma total homocysteine concentrations: a dietary controlled, crossover trial in healthy volunteers. Am J Clin Nutr 82, 553-558.

33. Virtanen JK, Voutilainen S, Rissanen TH, et al. (2006) High dietary Met intake increases the risk of acute coronary events in middle-aged men. Nutr Metab Cardiovasc Dis 16, 113-1120.

34. Hart SR, Mangoni AA, Swift CG, et al. (2006) Effect of Met loading on pulse wave analysis in elderly volunteers. Postgrad Med J 82, 524-527.

35. Bleys J, Navas-Acien A, Stranges S, et al. (2008) Serum selenium and serum lipids in US adults. Am J Clin Nutr 88, 416-423.

36. Stranges S, Laclaustra M, Ji C, et al. (2010) Higher selenium status is associated with adverse blood lipid profile in British adults. $J$ Nutr 140, 81-87.

37. Reeves PG (1997) Components of the AIN-93 diets as improvements in the AIN-76A diet. J Nutr 127, Suppl. 5, S838-S841.

38. Mueller AS, Pallauf J \& Most E (2002) Parameters of dietary selenium and vitamin $\mathrm{E}$ deficiency in growing rabbits. $J$ Trace Elem Med Biol 16, 47-55.

39. Lawrence RA \& Burk RF (1976) Glutathione peroxidase activity in selenium-deficient rat liver. Biochem Biophys Res Commun 71, 952-958.

40. Bradford MM (1976) A rapid sensitive method for the quantitation of microgram quantities of protein utilizing the principle of protein-dye binding. Anal Biochem 72, 248-254.

41. Vester B \& Rasmussen K (1991) High performance liquid chromatography method for rapid and accurate determination of homocysteine in plasma and serum. Eur J Clin Chem Clin Biochem 29, 549-554.

42. Hara A \& Radin NS (1978) Lipid extraction of tissues with a low-toxicity solvent. Anal Biochem 90, 420-426.

43. De Hoff JL, Davidson LM \& Kritchevsky D (1978) An enzymatic assay for determining free and total cholesterol in tissue. Clin Chem 24, 433-435.

44. Pfaffl MW (2001) A new mathematical model for relative quantification in real-time RT-PCR. Nucleic Acids Res 29, e45.

45. Mueller AS, Klomann SD, Wolf NM, et al. (2008) Redox regulation of protein Tyr phosphatase 1B by manipulation of dietary selenium affects the triglyceride concentration in rat liver. J Nutr 138, 2328-2336.

46. Mueller AS, Bosse AC, Most E, et al. (2009) Regulation of the insulin antagonistic protein Tyr phosphatase $1 \mathrm{~B}$ by dietary Se studied in growing rats. $J$ Nutr Biochem 20, 235-247.

47. Barnes KM, Evenson JK, Raines AM, et al. (2009) Transcript analysis of the selenoproteome indicates that dietary selenium requirements of rats based on selenium-regulated selenoprotein mRNA levels are uniformly less than those based on glutathione peroxidase activity. J Nutr 139, 199-206.

48. Bosse AC, Pallauf J, Hommel B, et al. (2009) Impact of selenite and selenate on differentially expressed genes in rat liver examined by microarray analysis. Biosci Rep (Epublication ahead of print version 14 Aug 2009).

49. Hill KE, Burk RF \& Lane JM (1987) Effect of selenium depletion and repletion on plasma glutathione and glutathionedependent enzymes in the rat. $J$ Nutr 117, 99-104.

50. Hill KE \& Burk RF (1985) Effect of selenium deficiency on the disposition of plasma glutathione. Arch Biochem Biophys 240, $166-171$
51. Hill KE \& Burk RF (1982) Effect of selenium deficiency and vitamin $\mathrm{E}$ deficiency on glutathione metabolism in isolated rat hepatocytes. J Biol Chem 257, 10668-10672.

52. Stead LM, Brosnan ME \& Brosnan JT (2000) Characterization of homocysteine metabolism in the rat liver. Biochem $J \mathbf{3 5 0}$, 685-692.

53. Blom HJ (2000) Consequences of homocysteine export and oxidation in the vascular system. Semin Thromb Hemost 26, 227-332.

54. Wallace HM \& Fraser AV (2004) Inhibitors of polyamine metabolism: review article. Amino Acids 26, 353-365.

55. Obeid O, Elfakhani M, Hlais S, et al. (2008) Plasma copper, zinc, and selenium levels and correlates with metabolic syndrome components of Lebanese adults. Biol Trace Elem Res 123, 58-65.

56. Karita K, Yamanouchi Y, Takano T, et al. (2008) Associations of blood selenium and serum lipid levels in Japanese premenopausal and postmenopausal women. Menopause 15, 119-124.

57. Dhingra S \& Bansal MP (2006) Modulation of hypercholesterolemia-induced alterations in apolipoprotein B and HMG-CoA reductase expression by selenium supplementation. Chem Biol Interact 161, 49-56.

58. Dhingra S \& Bansal MP (2005) Hypercholesterolemia and apolipoprotein B expression: regulation by selenium status. Lipids Health Dis 4, 28.

59. Dhingra S \& Bansal MP (2006) Attenuation of LDL receptor gene expression by selenium deficiency during hypercholesterolemia. Mol Cell Biochem 282, 75-82.

60. Obeid R \& Herrmann W (2009) Homocysteine and lipids: $S$-adenosyl Met as a key intermediate. FEBS Lett $\mathbf{5 8 3}$, $1215-1225$.

61. Zhao Y, Su B, Jacobs RL, et al. (2009) Lack of phosphatidylethanolamine $N$-methyltransferase alters plasma VLDL phospholipids and attenuates atherosclerosis in mice. Arterioscler Thromb Vasc Biol 29, 1349-1355.

62. Werstuck GH, Lentz SR, Dayal S, et al. (2001) Homocysteineinduced endoplasmic reticulum stress causes dysregulation of the cholesterol and triglyceride biosynthetic pathways. J Clin Invest 107, 1263-1273.

63. Taniguchi M, Nagao K, Inoue K, et al. (2008) Cholesterol lowering effect of sulfur-containing amino acids added to a soybean protein diet in rats. $J$ Nutr Sci Vitaminol 54, 448-453.

64. Kawasaki M, Funabiki R \& Yagasaki K (1998) Effects of dietary Met and cystine on lipid metabolism in hepatomabearing rats with hyperlipidemia. Lipids 33, 905-911.

65. Yabe D, Brown MS \& Goldstein JL (2002) Insig-2, a second endoplasmic reticulum protein that binds SCAP and blocks export of sterol regulatory element-binding proteins. Proc Natl Acad Sci U S A 99, 12753-12758.

66. Kidambi S \& Patel SB (2008) Cholesterol and non-cholesterol sterol transporters: ABCG5, ABCG8 and NPC1L1: a review. Xenobiotica 38, 1119-1139.

67. Duan LP, Wang HH \& Wang DQ (2004) Cholesterol absorption is mainly regulated by the jejunal and ileal ATP-binding cassette sterol efflux transporters Abcg5 and Abcg8 in mice. J Lipid Res 45, 1312-1323.

68. Woo CW, Siow YL, Pierce GN, et al. (2005) Hyperhomocysteinemia induces hepatic cholesterol biosynthesis and lipid accumulation via activation of transcription factors. Am J Physiol Endocrinol Metab 288, 1002-1010. 